\title{
Narrative Communication Messaging in Raising Public Awareness of Type 2 Diabetes Risk - A Multi- Perspective Cartography
}

\author{
Gillie Gabay ${ }^{1 *}$, Attila Gere ${ }^{2}$, Glenn Zemel $^{3}$ and Howard Moskowitz ${ }^{4}$ \\ ${ }^{1}$ School of Behavioral Sciences and Psychology, College of Management Academic Studies, 7 Rabin Blvd., Rishon-Letzion, Israel \\ ${ }^{2}$ Faculty of Sensory Evaluation, Szent István University, Budapest \\ ${ }^{3}$ DuPage Valley Anesthesiologists, LTD, Partner Bimicorp and Mind Genomics Associates, Chicago, IL, USA \\ ${ }^{4}$ Mind Genomics Associates, Inc. White Plains, NY, USA
}

*Corresponding author: Gillie Gabay, School of Behavioral Sciences and Psychology, College of Management Academic Studies, 7 Rabin Blvd., Rishon-Letzion, Israel

Received: September 13, 2020; Accepted: September 30, 2020; Published: October 08, 2020

\begin{abstract}
Objectives: Type 2 diabetes is the seventh leading cause of death and disability worldwide. Estimates suggest that by 2035,642 million people worldwide will suffer from diabetes. Higher awareness of risks of type 2 diabetes is a prerequisite to prevent or delay the onset of diabetes but, little attention has been paid to identifying effective communication messages to raise public awareness of risks of this disease and this is the focus of this study.

Methods: A conjoint based procedure facilitated an experimental design testing the power of narrative persuasion messages as driving awareness of risks of type 2 diabetes based on stability of utilities. The sample comprised 50 Americans recruited by Luc.id, Inc.

Results: Similarity in response patterns to messages uncovered three mindsets, each responsive to different messages. We identified effective messages for each mindset and developed a prediction tool assigning a person/group in the population to a sample mindset.

Discussion: Members of Mindset1 respond to empowering messages depicting members as having control, as able to modify their behaviors. Members of Mindset2 respond to messages presenting doctors as enhancing the health literacy of members and informing them of ways to prevent diabetes. Members of Mindset3 respond to messages presenting patients as a resource for learning, information, and support. Messages used in campaigns emerged as ineffective across mindsets
\end{abstract}

Conclusion: The prediction tool assigning people to mindsets may enable professionals to detect the psychological mind-set of an individual and drive health behavior changes using effective messaging.

Keywords: Awareness, Communication, Diabetes, Narrative-Messaging, Public, Mindsets

Type 2 diabetes is a major cause of increasing mortality incurring vast expenditures. Direct costs of type 2 diabetes account for $\$ 1.31$ trillion and additional indirect costs account for $35 \%$ of the total burden [1]. Type 2 diabetes is one of five leading causes of premature death in high-income countries [2]. In 2017, around 415 million adults suffered from Type 2 diabetes [2]. Estimates suggest that over the next decade, 642 million adults will suffer from type 2 diabetes [2]. Moreover, type 2 diabetes, thus far diagnosed among adults, is now expanding to adolescents and children, making it THE epidemic of the $21^{\text {st }}$ century [3]. So far, all interventions to maintain Glycemic control achieved sub-optimal outcomes [3-7]. Lack of Glycemic control leads to progress of type 2 diabetes resulting in a range of health complications, morbidity and disability [2].

Tremendous efforts to halt the expansion of type 2 diabetes involved: behavior-modification programs, pharmacological interventions and educational interventions. Whereas policy makers viewed these efforts as promising means to affect modifiable determinants of type 2 diabetes (i.e., obesity, sedentary lifestyles, smoking, stress), research evidence remains inconsistent [6-8]. Moreover, most interventions failed as program-compliance challenged patients and due to the global shortage in clinicians which limited program accessibility [9-14]. Research on pharmacological interventions suggests that lifestyle modifications, are, in fact, more efficacious [15]. No findings of other specific pharmacological interventions were published in papers. Last, research on educational interventions demonstrated contradictory results exposing provision barriers which inhibited intervention deployment $[16,17]$. In sum, to date, hypotheses of evaluation studies for interventions for control, prevention, and delay of the onset of type 2 diabetes, have not been corroborated. The prevalence of diabetes and the per capita expenditures of diabetes (direct and indirect costs) are rising and while they may be grounds for diabetes prevention, the awareness level among prediabetes and the rate of preventing interventions are low and of great concern [18].

Two recent studies that tested awareness among high risk British adults and among Americans, reported that half of participants 
demonstrated gaps in awareness of risks, symptoms and related behaviors [19,20]. Researchers recently acknowledged that individuallevel prevention approaches are inadequate and thus unable to reverse epidemic trends, costly, and not scalable for targeting the healthy population [21]. Since lack of public information is a major barrier to risk awareness, researchers suggest the importance of increasing vigilance in reducing risks of type 2 diabetes by addressing gaps in public awareness $[2,3,15,19,22,23]$.

Numerous institutions, including the World Health Organization, have recommended mass communication messaging to improve public awareness [22]. Studies in medicine, public health, and health communication, however, targeted patients rather than the healthy population [20-22]. Creating public awareness of the healthy population was thus far seen as less important than improving practices of patients [22]. The few studies that tested communication messaging for public awareness regarding general health issues, featured linkages among awareness behavior and health outcomes $[23,24]$. While research on communication messaging in general health topics is growing, the topic of communication messaging to the healthy population in type 2 diabetes, is unexplored [21,23-25].

One study presented a successful communication messaging campaign on determinants of type 2 diabetes but its reach was limited as it only engaged youth [21]. Another study on communication messaging in type 2 diabetes revealed that awareness of risks increased in the one Indian city where it was conducted [26]. Whereas studies on communication messaging in type 2 diabetes are scarce, findings of these two studies suggest that public campaigns may effectively raise awareness among many different segments of the healthy population and may reverse current concerning paths of behavioral trends in modifiable drivers of type 2 diabetes [21]. Since all groups in the population suffer from the burden of type 2 diabetes, this epidemic should be addressed, as other healthy issues, by effective communication messaging. An alternative as yet unexplored way to respond to previous calls to reduce risks of type 2 diabetes is to test and optimize messaging among healthy people. A systematic examination of effective campaigns indicates that in health disparities narrative messages have a persuasive impact on attitude change and behavioral modifications [27,28]. Also, facets that draw on the narrative persuasion theory, have been reported to bring individuals in the population to accept greater responsibility for their health [28]. In this study we draw on the theory of narrative persuasion in the daily life experiences of healthy people touching on risk awareness of Type 2 diabetes.

\section{The Theoretical Framework and Hypotheses Development}

A narrative comprises cohesive and coherent statements that may make up a story with an identifiable beginning, middle, and end and provide information about a daily phenomenon [29]. Narratives entail an integration of attention, imagery, and feelings [30]. Narrative communication messages either convey a point to another party or receive information from another party [31]. Narratives are a scientific way of relying on empirical and experimental methods to discover, describe, or elucidate some domain of interest through which we develop our understanding of the world and the distinctive ways of constructing reality $[29,32]$. One's engagement with a narrative may result in one's endorsement of modified attitudes and behaviors [33]. Engagement is affected by the attentional focus and one's identification with the narrative [34]. Prior studies that tested the effect of narrative persuasion, however, did not focus on health $[35,36]$. Narrative messages may be effective in the health-behavior context, as they are the basic mode of human interaction that we use in our day-to-day lives to influence others [32].

Narrative messages in health communication entail anecdotes, testimonials, and stories [33]. In health communication several moderators were found to shape the narrative's extent of persuasion: the health behavior, the delivery channel, the research design and the sample characteristics [35]. Previous studies tested the effect of narratives on health-related attitudes and intentions which were strongly associated with health behaviors [37-42].

Previous studies relied on behavioral modeling of exemplars with whom the audience identified $[43,44]$. Identification with an exemplar was key in the persuasion effect the narrative yielded [38,40,45-47]. Narratives of an exemplar delivered via audio and video which aimed at prevention, had a greater persuasion effect than did print-based narratives aiming at cessation [35]. Crafting engaging narratives, however, requires lengthy stories which are hard to apply in public health communication [43]. Some brief print-based narrative messages regarding risks of type 2 diabetes may have a stronger effect than will others.

\section{Hypothesis 1}

Different narrative communication messaging will have a different effect on perceived risks of Type 2 diabetes. Since the narrative persuasion theory is interpretive, it explores the impact of each message asking: for whom; under what circumstances; how; and when does each message achieve optimum effects $[48,49]$. The extent to which narrative messages regarding risks of type 2 diabetes will influence individuals may, therefore, differ among them. Narrative messages that are employed specifically for type 2 diabetes, could be more effective than general health related messaging because they touch on well-known determinants of type 2 diabetes. We hypothesize that the ability of narrative messages to raise awareness of type 2 diabetes risks, may depend, in part, on the extent to which people "identify" with the different narrative messages [31]. Narrative messaging, therefore, may carry a different appeal to homogeneous groups of people who are defined by similarity in their pattern of responses to narrative persuasion messages (i.e. mindset-segments) regarding risks in type 2 diabetes.

\section{Hypothesis 2}

Different narrative communication messages regarding risk of type 2 diabetes will carry a different appeal for different people by mindset segments. Narrative messages may also impact beliefs of healthy individuals about who is responsible for addressing and engaging in health behaviors, thereby, shaping their perceptions about their risks of type 2 diabetes [50]. 


\section{Hypothesis 3}

Different narrative communication messages will have a greater impact on perceived responsibility for health behaviors to avoid risks of type 2 diabetes.

\section{The Current Study}

Studies that tested the effect of specific print-based narrative messaging on identification and on attitudes towards the messaging by mindset-segmentation regarding urgent health problems are scant [35]. This study is in response to previous calls to explore under what condition a print-based narrative messaging may influence attitudes [35]. This study attempts to explore the effect of various elements of narrative messaging on the identification with the message and on risk awareness. While previous studies mostly included lab experiments or field experiments, this study employs an experimental research design [35]. This study is an important step in beginning to close the literature gap by testing specific brief narrative messaging for awareness of type 2 diabetes risk among healthy people. The aim of this study was to fill the above theoretical, methodological and practical gaps in the state of the art. Theoretically, to best of our knowledge, studies that tested specific narrative messaging for healthy populations regarding risks of type 2 diabetes are scant [29]. Also, the application of the narrative persuasion theory in the context of diabetes prevention while measuring one's identification with elements of the message is an underutilized and underexplored research area [43]. Methodologically, we test unexplored communication messages among healthy individuals through a multi-disciplinary view, examining narrative messaging from different perspectives. In terms of practice, this research project assesses the impact of a variety of narrative messages as drivers of perceived risk of type 2 diabetes and proses to apply the knowledge by a classification tool developed based on the impact of the narrative communication messages.

\section{Research Design and Methods}

Conjoint measurement refers to a class of research procedures in which the respondent is provided with a set of systematically varied combinations of features (questions and answers) and rates the combination, providing an estimate for the part-worth utility of each answer [51]. Since our objective is to develop a model of messaging for each respondent, the question of sample size devolves into a question of the number of respondents needed before the average model across respondents becomes stable [52]. Whereas sociologists study behaviors of large groups of people and deal with the percent of people who achieve a given score, experimental psychologists deal with individual behavior focusing on the magnitude of a response and looking at means, and the stability of the mean as a predictor of the performance of the dependent variable. Thus, in Mind-Genomics, since results are based upon the average rating assigned to a narrative statement, the size of the sample is not a question of the stability of the average rating, but rather the stability of the model averaged across the different respondents. Data on utilities from several conjoint measurement samples confirm previous observations on base size studies and indicates that much of the information can be obtained with lower bases than the typical base size and the same conclusions can be made with base sizes around 50 [53]. Therefore, the sample comprised 50 respondents, healthy American adults with 25 females and 25 males, ages 31-44 ( $\mathrm{n}=12) ; 45-55(\mathrm{n}=18)$ and $56+(\mathrm{n}=18)$. Respondents were selected by Luc.id, Inc., a panel provider of online samples. Respondents represent a cross-section of the typical respondent.

We structured messages that tell a story and attend to coherent statements with a clear beginning, middle, and end [54,55]. We designed the narrative messages and shaped the rating question to influence cognitive attention, thereby, mediating between the content and the intention. Since narrative communication messaging that relates to only one perspective, may carry bias, reducing the complexity in our world and inhibiting effective awareness for different target audiences, this study combines among narrative persuasion messages from several perspectives: the psychological perspective (individual's behavior), the sociological perspective (perceived contextual factors), the economics perspective (social structural elements and costs) and the health management perspective (health services). We structure messages by an experimental design guided by Mind-Genomics ${ }^{\circledR}$, a new conjoint based scientific approach, best described a 'cartography of the mind.' Mind-Genomics examines responses of people to different stimuli in daily life [56]. Mind-Genomics maps an experience by identifying its different facets, determining to what facets the person attends, and how important each facet is for each person. MindGenomics reveals how people react to the specifics of the messaging, looking at the nuances, whereas accounting for the richness of the experience. Mind-Genomics ${ }^{\oplus}$ segments different groups of people by their different viewpoints, so-called mindsets.

\section{Outcome and Independent Variables}

The dependent variable is perceived risks of type 2 diabetes, measured by the extent of importance each respondent attributes to each driver of risk on a 1-9 rating scale. Four categories of narrative statements: determinants of type 2 diabetes, healthcare needs, expectations and support and responsibility. Each category comprised four narrative messages about type 2 diabetes, each from different disciplines. Each respondent evaluated a unique set of 24 combinations of narrative messages that are each independent of all other messages by experimental design, with each category comprising a minimum of two statements, or a maximum of four statements. By virtue of the Mind-Genomics ${ }^{\bullet}$ experimental design, the 16 messages are statistically independent of each other. The structure of the 24 combinations remained the same, ensuring statistical independence of the predictor variables for subsequent regression. Effective messages regarding risks of type 2 diabetes need not only proper framing, but also avoiding the activation of negative attitudes and resistance to the message itself [57]. The specific combinations changed, however, due to a permutation scheme allowing the experiment to cover many more of the possible combinations of messages using today's standard experimental designs $[57,58]$.

With 50 respondents, the researcher covers 1200 messages (50x24), rather than repeating the same 24 messages 50 times. Table 1 presents categories and messages per category. Respondents rated the importance of each message in shaping their perceived risk of type 
Table 1: The Four Categories and the Four Narrative Messages in Each Category.

\begin{tabular}{|l|l|}
\hline & Question A: type 2 diabetes determinants \\
\hline A1 & By living longer there is a greater chance of suffering from type 2 Diabetes \\
\hline A2 & Type 2 diabetes is dangerous without treatment \\
\hline A3 & Diet and exercise are key to type 2 Diabetes prevention \\
\hline A4 & Type 2 Diabetes is the most profound disease of this century \\
\hline & Question B: Healthcare Needs \\
\hline B1 & It's OK to self-manage type 2 diabetes \\
\hline B2 & People with type 2 diabetes use a lot of health services \\
\hline B3 & Frequent doctor promote medication-adherence \\
\hline B4 & Type 2 diabetes requires a lot of medications \\
\hline & Question C: Expectations \\
\hline C1 & It's a doctor's role to educate patients about type 2 diabetes \\
\hline C2 & The internet is all you need to learn about type 2 diabetes \\
\hline C3 & A doctor should refer people to reliable educational materials about type 2 diabetes \\
\hline C4 & People should know all the possible treatments of type 2 diabetes \\
\hline & Question D: Support \\
\hline D1 & Family support is important to manage diabetes \\
\hline D2 & Learning how others cope with challenges is beneficial \\
\hline D3 & Participation in workshops helps prevent type 2 diabetes \\
\hline D4 & Belonging to a community helps maintain health behaviors that prevent type 2 diabetes \\
\hline & \\
\hline
\end{tabular}

2 diabetes on a 1-9 rating scale. Response biases were overcome by presenting the respondent with combinations of messages assembled by an experimental design, which mixes and matches different types of ideas to test combinations of messages by categories that drive the perceived risk of type 2 diabetes [20,31]. To test the instrument, reliability was established by the split-half method. The entire data set was divided into two equal groups, with each respondent contributing data equal to both groups. Each group is used to estimate the coefficient of the messages. Three sets of coefficients were created: from the total panel, and from each half-set. The two half sets of data were highly correlated with data for the total panel ( 0.90 for group 1 ; 0.87 for group 2).

\section{Statistical Analysis}

The experimental design ensures that an individual-level regression model can be run on the data. The original 9-point rating scale, anchored at both ends, was transformed to a binary scale (i.e., Ratings of 1-6 were considered 'not important,' and transformed to 0 . Ratings of 7-9 were transformed to 100), to denote that these were important. The data were then subject to Ordinary Least-Squares regression (OLS). The regression equation was run for total panel and for each key subgroup (total, gender, age), incorporating all relevant data into one regression model for the group. Whereas the regression model suggests that a standard error around 4.0 or so characterizes the different coefficients, as a rule of thumb in conjoint coefficients of 8 or higher tend to be statistically significant and to co-vary with measurable external behavior which might serve as a validation.

In conjoint analysis, regression coefficients reveal the impact (degree of agreement) of communications of messages. The pattern of strong performing (positive) coefficients across different subgroups, suggest the nature of what is important for the respondents who are assigned to a mindset which is created by clustering the coefficients across all of the messages. There is no need for Beta values for the coefficient because in the modeling the messages are represented as either 0 (absent from the combination) or 1 (present in the combination) [57].

\section{Results}

The rated importance of the information presented by the narrative message on type 2 diabetes varied across groups. Respondents in the youngest group rated information as unimportant. Members of the other age groups rated the information as moderately important and very important. Males had a higher additive constant indicating that they will require less specific information to reach risk awareness than will females. The differences in response patterns of different groups showed that there are three distinct mind-sets. Table 2 presents the coefficients for the total panel and for the three mind-set segments reflecting different patterns of responses to the importance of each narrative statement contributing to the perceived risk as emerged

Table 2: Coefficients for total panel and the three emergent mindsets based upon the patterns of coefficients of narrative messages.

\begin{tabular}{|c|c|c|c|c|c|}
\hline & & Total & Mindset 1 & Mindset 2 & Mindset 3 \\
\hline & Base & 50 & 18 & 13 & 19 \\
\hline & Additive constant & 59 & 62 & 43 & 67 \\
\hline & $\begin{array}{l}\text { Mind-Set } 1 \text { - The patient is in control, and } \\
\text { must take responsibility (psychology) }\end{array}$ & & & & \\
\hline A3 & $\begin{array}{l}\text { Diet and exercise are key to type } 2 \text { Diabetes } \\
\text { prevention }\end{array}$ & 8 & 17 & 4 & 3 \\
\hline \multirow[t]{2}{*}{ A2 } & $\begin{array}{l}\text { TYPE } 2 \text { DIABETES is dangerous without } \\
\text { treatment }\end{array}$ & 7 & 14 & 8 & -1 \\
\hline & $\begin{array}{l}\text { Mind-Set } 2 \text { - The doctor is very important } \\
\text { (sociology) }\end{array}$ & & & & \\
\hline C3 & \begin{tabular}{|l|} 
A doctor should refer patients to \\
educational materials about type 2 Diabetes
\end{tabular} & -3 & -13 & 20 & -11 \\
\hline $\mathrm{C} 1$ & $\begin{array}{l}\text { It's a doctor's role to educate patients about } \\
\text { type } 2 \text { Diabetes }\end{array}$ & -4 & -13 & 16 & -9 \\
\hline \multirow[t]{2}{*}{$\mathrm{C} 4$} & $\begin{array}{l}\text { A patient should know all the possible } \\
\text { treatments of Type } 2 \text { Diabetes }\end{array}$ & 0 & -3 & 12 & -7 \\
\hline & $\begin{array}{l}\text { Mind-Set } 3 \text { - Help from others is } \\
\text { important (Social structure \& Services) }\end{array}$ & & & & \\
\hline D3 & $\begin{array}{l}\text { Participation in workshops for patients } \\
\text { helps manage Type } 2 \text { Diabetes }\end{array}$ & 2 & -12 & -2 & 19 \\
\hline D1 & $\begin{array}{l}\text { Family support is important to manage } \\
\text { type } 2 \text { Diabetes }\end{array}$ & 5 & 0 & 0 & 16 \\
\hline D4 & $\begin{array}{l}\text { Belonging to a community of patients helps } \\
\text { support others with type } 2 \text { Diabetes }\end{array}$ & 1 & -10 & -3 & 15 \\
\hline B3 & $\begin{array}{l}\text { Frequent doctor visits help adherence to } \\
\text { type } 2 \text { Diabetes treatment }\end{array}$ & 4 & 4 & -8 & 11 \\
\hline \multirow[t]{2}{*}{ D2 } & $\begin{array}{l}\text { Learning how others cope with type } 2 \\
\text { Diabetes is beneficial }\end{array}$ & 3 & -5 & 4 & 8 \\
\hline & $\begin{array}{l}\text { Elements which are not key to any mind- } \\
\text { set (Cost \& Health services) }\end{array}$ & & & & \\
\hline B2 & $\begin{array}{l}\text { People with type } 2 \text { Diabetes use a lot of } \\
\text { health services }\end{array}$ & -3 & -4 & -13 & 2 \\
\hline B4 & $\begin{array}{l}\text { Type } 2 \text { Diabetes requires a lot of } \\
\text { medications }\end{array}$ & -5 & 5 & -22 & -4 \\
\hline A4 & $\begin{array}{l}\text { Type } 2 \text { Diabetes is the most profound } \\
\text { disease of this century }\end{array}$ & -3 & 4 & 0 & -10 \\
\hline B1 & It's OK to self-manage the type 2 Diabetes & -17 & -14 & -27 & -13 \\
\hline Al & $\begin{array}{l}\text { By living longer there is a greater chance of } \\
\text { suffering from Type } 2 \text { Diabetes }\end{array}$ & -9 & 1 & -5 & -20 \\
\hline $\mathrm{C} 2$ & $\begin{array}{l}\text { The internet is all you need to learn about } \\
\text { diabetes }\end{array}$ & -26 & -24 & -4 & -42 \\
\hline
\end{tabular}


from Mathematical K-clustering analysis. Figure 1 presents sample distribution by mind-set segments and Figure 2 presents sample distribution into mindset-segments by age group.

\section{Applying Narrative Communication Messaging for Raising Awareness to Type 2 Diabetes}

To identify which communication messaging should be used in practice, we applied the personal viewpoint identifier (PVI) which is created a new for each study and in this case revealed the mindset of an individual through a simple, 30-second interaction. The respondent completed a short, 6-question evaluation, with the pattern

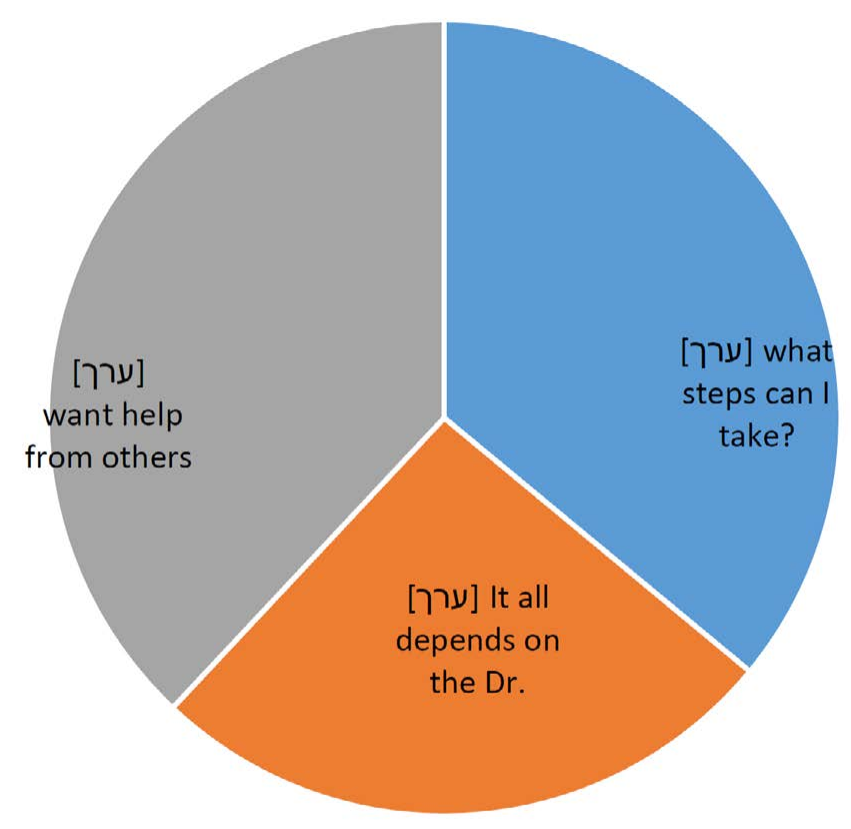

- Mind-set 1 = Mind-set 2 Mind-set 3

Figure 1: Risk Awareness of Type 2 Diabetes in Healthy Individuals.

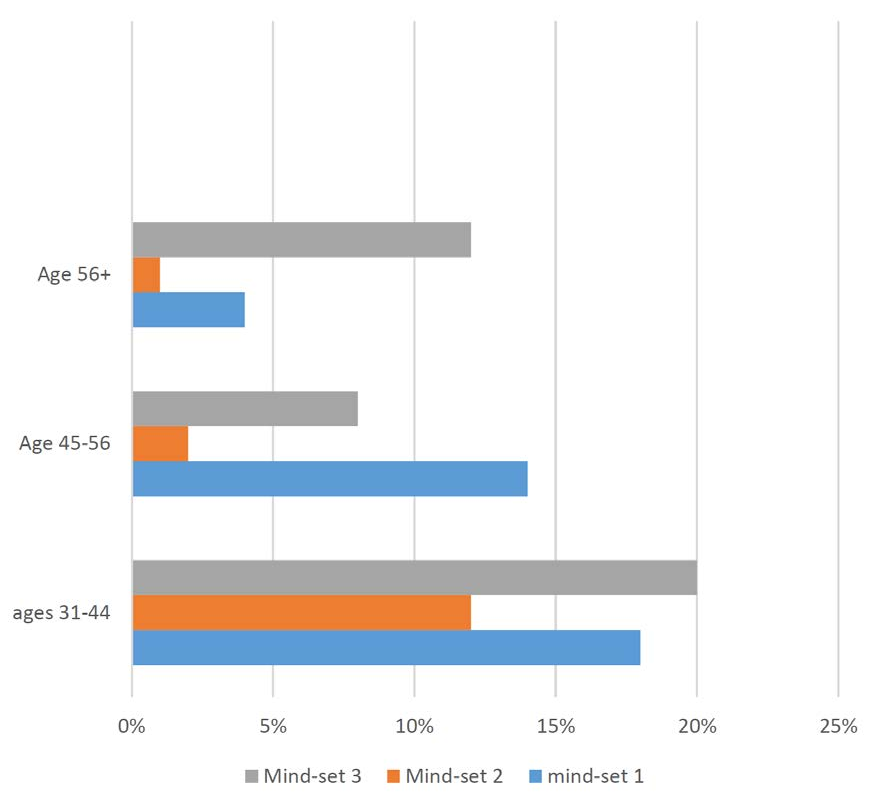

Figure 2: Distribution into Mindsets by Age. of the responses linked to membership in one of the three mind-sets. The six most discriminating narrative messages were chosen to create the PVI which then created a binary scale on which new participants may rapidly indicate their answers. Based on these answers, the MindGenomics system instantly presents the sample mind-set membership for the individual in the population, who can then be given the most effective messaging for the mind-set to which the individual appears to belong. The PVI is available at: http://162.243.165.37:3838/TT37

\section{Discussion}

This study tested narrative persuasion messages as drivers of public awareness of risks of type 2 diabetes. This study makes theoretically, methodologically and practical contribution. Theoretically, this study extended the narrative persuasion theory testing narrative communication messaging in the health context, focusing on risk awareness in type 2 diabetes among healthy people. Methodologically, this study explored narrative communication messaging through a multi-disciplinary view, from different perspectives applying an innovative conjoint-analysis procedure. Practically, findings direct professionals on a local level and on a national health policy level to use narrative communication messaging that impact the risk perception of healthy people, by mind-set segments, regarding type 2 diabetes. Findings show that all study hypotheses were corroborated and also suggest that just as narrative messaging was effective in public campaigns on general health issues, it can be effective for public campaigns targeting awareness of risks in type 2 diabetes for the healthy population [21].

As for hypothesis 1, stating that different narrative communication messaging will have a different effect on perceived risks of type 2 diabetes, findings suggest that a number of narrative messages, that may be used on local level by professionals appear to be ineffective, and may create antagonism and anxiety, rather than raise public awareness of risks of type 2 diabetes and navigate individuals towards the adoption of healthy behaviors. Such messages are: People with type 2 diabetes use a lot of health services; Type 2 diabetes requires lots of medications; Type 2 diabetes is the most profound disease of this century and; living longer raises the risk of suffering from Type 2 diabetes. This finding may be attributed to the underlying communication orientation in these narrative messages. Ineffective messages fall under the category of content-oriented messaging which focuses on 'what the public should know about type 2 diabetes'. Whereas contentoriented messaging is popular, it does not promote behavioral change, particularly compared to change-process oriented communication which was found to be a 'make or break' factor in behavioral modifications, including in type 2 diabetes [56,57].

As for hypothesis 2 stating that different narrative communication messages regarding risk of type 2 diabetes will carry a different appeal for different people by mindset segments, data show that response patterns to narrative messages differed among groups of people, differentiating them by mindset segments. People who are members of mind-set1 will react to messages depicting individuals as having control and able to take responsibility for their health stressing the psychology view (e.g., Diet and exercise are key to type 2 diabetes prevention; Type 2 diabetes is dangerous without treatment). This 
finding supports previous findings on the role of communication in promoting perceived control in behavioral modifications [56,57]. Outreach to people belonging to mindset 1 should entail information on: steps in the behavioral change process; what may assist them throughout the change process; what internal and external resources they may use; and how they may overcome barriers [58].

Messaging is to be inspirational and hopeful enhancing selfefficacy $[57,58]$. People who belong to Mindset2, the smallest mindset segment, will positively react to narrative messages depicting the doctor as a resource stressing the sociological view (e.g., A doctor should refer patients to educational materials about type 2 diabetes; It's the doctor's role to educate patients about type 2 diabetes; A patient should know all the possible treatments of type 2 diabetes). This finding supports previous studies on the sociological role of trust in physicians and the public expectation from physician to inspire them in adopting healthy behaviors $[57,59]$.

People who are members of Mindset 3, will positively react to narrative messages depicting help from others stressing the economics and health management view (e.g., Participation in workshops helps prevent type 2 diabetes; Belonging to a community helps maintain healthy behaviors to prevent type 2 diabetes; learning how others cope with challenges is beneficial), focusing on community and available supporting health services. These findings support previous studies that claimed that communication messaging in national public campaigns may improve awareness of type 2 diabetes risks in healthy populations and among different segments of the population $[23,29]$. Study findings echo previous findings on the strong impact that narrative messaging may have on attitude change and behavioral modifications [29,31]. As for hypothesis 3 , stating that different narrative communication messages will have a greater impact on perceived responsibility of individuals to modify their health behaviors and avoid risks of type 2 diabetes, the membership of people to mindset-segments entailed differences in their perceived responsibility. Perceived responsibility for reducing risks of type 2 diabetes ranged from self- responsibility (segment 1 ) to doctor's responsibility (segment 2 ) and to community as having a role in helping its healthy members prevent risks of type 2 diabetes. Findings support previous studies stating that narrative messaging may play an important role in health communication campaigns to influence attitudes, intentions, and health behaviors [35].

\section{Practice Implications}

The knowledge derived from this research enables policy makers to accord the most effective narrative communication messaging to each person and group in the population, by the mind-set segmentation, in the sample. The segmentation by mindset suggests that a public communication campaign with the same messages for all, will be futile. When designing campaigns to raise public awareness of risks of type 2 diabetes, content-oriented messages should be omitted. Figures 1 and 2 indicate that segments of mindsets 1 and 3 are about the same size but as age increases, on one hand the perceived importance of this information increases but perceived individual's responsibility to modify risk behaviors decreases. People in the oldest group (56+) who are under the highest risk of type 2 diabetes, attribute the highest authority to doctors compared to people in other age groups and expect support of doctors, the community and health services (i.e. workshops) in behavior modification to prevent type 2 diabetes. These data suggest that in campaigns targeting people who are older than 45 years old, messaging is to be based on the change-process orientation rather than content-oriented. Last, three campaigns are to be designed, each targeting people in a different mindset segments and each focusing on a different perspective. One campaign entailing messages of perceived control over health (psychology), another campaign entailing messages of advice from trusted professionals (sociology) and the third campaign offering health-services (i.e., workshops and mentorship of supporting individuals) (health management) for maintaining healthy behaviors.

\section{Future Studies}

Future studies may continue to test unique features of brief printed-based narrative messaging and their effect on health attitudes and intentions. Future studies may also broaden our knowledge as to the effect of culturally tailored messaging on risk awareness in urgent health problems.

\section{Conclusion}

To sum, this study closed a knowledge gap in the state of the art examining multi-perspective narrative persuasive messaging as means to raise awareness of type 2 diabetes in healthy populations. This study presents a new approach to raise public awareness of risks of type 2 diabetes through narrative messaging by mindset segmentation. To enhance effectiveness in raising awareness of type 2 diabetes risks and to wisely allocate budgets, health professionals, policy makers and public campaign designers, are urgently called upon to use the VPI, ask the right few questions to identify the belonging of each individual in the healthy population to a mindset segment in the sample and use the appropriate narrative communication messaging per segment in raising awareness. The theoretical, methodological and practical knowledge derived from this study will enable policy makers and professionals to accord the most effective narrative communication messaging to each person and group in the population, by the mindset segmentation, in a cost-effective manner.

\section{References}

1. Bommer C, Heesemann E, Sagalova V, Manne-Goehler J, Atun R, et al. (2017) The global economic burden of diabetes in adults aged 20-79 years: a cost-of-illness study. The Lancet Diabetes \& Endocrinology 5: 423-430.

2. Gregg EW (2017) The changing tides of the type 2 diabetes epidemic-smooth sailing or troubled waters ahead? Kelly West Award Lecture 2016. Diabetes Care 40: 12891297. [crossref]

3. Rubin RR, Peyrot M, Siminerio LM (2006) Health care and patient-reported outcomes: results of the cross-national Diabetes Attitudes, Wishes and Needs (DAWN) study. Diabetes Care 29: 1249-1255. [crossref]

4. Tiv M, Viel JF, Mauny F, Eschwege E, Weill A, et al. (2012) Medication adherence in type 2 diabetes: the ENTRED study 2007, a French population-based study. PLoS One 7: e32412.

5. Carratalá-Munuera FMC, Gil-Guillen VF, Orozco-Beltran D, Navarro-Pérez J, CaballeroMartínez F, et al. (2013) Barriers associated with poor control in S panish diabetic patients. A consensus study. International Journal of Clinical Practice 67: 888-894.

6. Shadi F, Mohammad AS, Amir HZ, Amini M (2011) Effect of pharmacist-led patient education on glycemic control of type 2 diabetics: a randomized controlled trial. Journal of Research in Medical Sciences 16: 43-49. [crossref] 
7. Walker EA, Shmukler C, Ullman R, Blanco E, Scollan-Koliopoulus M, et al. (2011) Results of a successful telephonic intervention to improve diabetes control in urban adults: a randomized trial. Diabetes Care 34: 2-7. [crossref]

8. American Diabetes Association (2013) Standards of medical care in diabetes. Diabetes Care 36: S11-S66.

9. Atlas, Diabetes (2015) International diabetes federation. IDF diabetes atlas. Brussels: International Diabetes Federation.

10. Guangwei L, Zhang P, Wang J, Gregg EW, Yang W, et al. (2008) The long-term effect of lifestyle interventions to prevent diabetes in the China Da Qing Diabetes Prevention Study: a 20-year follow-up study. The Lancet 371: 1783-1789.

11. Diabetes Prevention Program Research Group (2009) 10-year follow-up of diabetes incidence and weight loss in the Diabetes Prevention Program Outcomes Study. The Lancet 374: 1677-1686.

12. Diabetes Prevention Program (DPP) Research Group (2002) The Diabetes Prevention Program (DPP): description of lifestyle intervention. Diabetes Care 25: 2165-2171.

13. Sepah S, Cameron LJ, Peters AL (2015) Long-term outcomes of a Web-based diabetes prevention program: 2-year results of a single-arm longitudinal study. Journal of Medical Internet Research 17: e92. [crossref]

14. Subramanian K, Inuka M, Chellapilla V (2017) Overcoming the challenges in implementing type 2 diabetes mellitus prevention programs can decrease the burden on healthcare costs in the United States. Journal of Diabetes Research. [crossref]

15. Diabetes Prevention Program Research Group (2013) The 10-year cost-effectiveness of lifestyle intervention or metformin for diabetes prevention: an intent-to-treat analysis of the DPP/DPPOS. Diabetes Care 36: 4172-4175. [crossref]

16. Butcher MK, Karl K, Vanderwood TO, Hall D, Helgerson GSD, et al. (2011) Capacity of diabetes education programs to provide both diabetes self-management education and to implement diabetes prevention services. Journal of Public Health Management and Practice 17: 242-247. [crossref]

17. Bloomfield HE, Greer N, Kane R, Wilt JT (2017) Effects on health outcomes of a Mediterranean diet with no restriction on fat intake. Annals of Internal Medicine 166: 378-379.

18. Riddle MC, Herman WH (2018) The cost of diabetes care-an elephant in the room. Diabetes Care 41: 929-932. [crossref]

19. Reem K, Slater N, Sahi A, Mepani D, Lalji K, et al. (2019) Type 2 Diabetes: how informed are the general public? A cross-sectional study investigating disease awareness and barriers to communicating knowledge in high-risk populations in London. BMC Public Health 19: 138. [crossref]

20. Okosun IS, Davis-Smith M, Seale JP (2012) Awareness of diabetes risks is associated with healthy lifestyle behavior in diabetes free American adults: evidence from a nationally representative sample. Primary Care Diabetes 6: 87-94. [crossref]

21. Rogers EA, Fine S, Handley MA, Davis H, Kass J, et al. (2014) Development and early implementation of the bigger picture, a youth-targeted public health literacy campaign to prevent type 2 diabetes. Journal of Health Communication 19: 144-160. [crossref]

22. Niederdeppe JQ, Bu L, Porismita B, Kindig DA, Robert SA (2008) Message design strategies to raise public awareness of social determinants of health and population health disparities. The Milbank Quarterly 86: 481-513. [crossref]

23. Randolph KA, Whitaker P, Arellano A (2012) The unique effects of environmental strategies in health promotion campaigns: a review. Evaluation and Program Planning 35: $344-353$

24. Robert SA, Booske BC (2011) US opinions on health determinants and social policy as health policy. American Journal of Public Health 101: 1655-1663. [crossref]

25. Clarke CE, Niederdeppe J, Lundell HC (2012) Narratives and images used by public communication campaigns addressing social determinants of health and health disparities. International Journal of Environmental Research and Public Health 9: 4254-4277. [crossref]

26. Siegel K, Venkat Narayan (2008) The Unite for Diabetes campaign: overcoming constraints to find a global policy solution. Globalization and Health 4: 1-8. [crossref]

27. Somannavar S, Lanthorn H, Deepa MR, Pradeepa MR, Mohan V (2008) Increased awareness about diabetes and its complications in a whole city: Effectiveness of the "prevention, awareness, counselling and evaluation [PACE] Diabetes Project [PACE6]. Journal of the Association of Physicians of India 56: 495-502. [crossref]
28. Lundell HC, Niederdeppe J, Clarke CE (2013) Exploring interpretation of complexity and typicality in narratives and statistical images about the social determinants of health. Health Communication 28: 486-498. [crossref]

29. Hinyard LJ, Kreuter MW (2007) Using narrative communication as a tool for health behavior change: a conceptual, theoretical, and empirical overview. Health Education and Behavior 34: 777-792. [crossref]

30. Moyer-Gusé E (2008) Toward a theory of entertainment persuasion: Explaining the persuasive effects of entertainment-education messages. Communication Theory 18: 407-425.

31. Schank R, Berman T (2002) The pervasive role of stories in knowledge and action.

32. Gabay G (2019) Patient self-worth and communication barriers to trust of Israeli patients in acute-care physicians at public general hospitals. Qualitative Health Research 29: 1954-1966. [crossref]

33. Bilandzic H, Busselle RW (2011) Enjoyment of films as a function of narrative experience, perceived realism and transportability. Communications 36: 29-50.

34. Busselle R, Bilandzic H (2009) Measuring narrative engagement. Media Psychology 12: 321-347.

35. Shen F, Sheer VC, Li R (2015) Impact of narratives on persuasion in health communication: A meta-analysis. Journal of Advertising 44: 105-113.

36. Van Laer T, De Ruyter K, Visconti LM, Wetzels M (2014) The extended transportationimagery model: A meta-analysis of the antecedents and consequences of consumers' narrative transportation. Journal of Consumer Research 40: 797-817.

37. Morgan SE, Movius L, Cody MJ (2009) The power of narratives: The effect of entertainment television organ donation storylines on the attitudes, knowledge, and behaviors of donors and non-donors. Journal of Communication 59: 135-151.

38. Moyer-Gusé E, Chung AH, Jain P (2011) Identification with characters and discussion of taboo topics after exposure to an entertainment narrative about sexual health. Journal of Communication 61: 387-406.

39. Moyer-Gusé E, Nabi RL (2010) Explaining the effects of narrative in an entertainment television program: Overcoming resistance to persuasion. Human Communication Research 36: 26-52.

40. Murphy ST, Frank LB, Chatterjee JS, Baezconde-Garbanati L (2013) Narrative versus non-narrative: The role of identification, transportation, and emotion in reducing health disparities. Journal of Communication 63: 116-137. [crossref]

41. Van Leeuwen L, Renes RJ, Leeuwis C (2013) Televised entertainment-education to prevent adolescent alcohol use: Perceived realism, enjoyment, and impact. Health Education \& Behavior 40: 193-205. [crossref]

42. Fishbein M, Ajzen I (2010) Prediction and change of behavior: The reasoned action approach. Taylor and Francis Publishing, New York.

43. Kim HS, Bigman CA, Leader AE, Lerman C, Cappella JN (2012) Narrative health communication and behavior change: The influence of exemplars in the news on intention to quit smoking. Journal of Communication 62: 473-492. [crossref]

44. Tal-Or N, Cohen J (2010) Understanding audience involvement: Conceptualizing and manipulating identification and transportation. Poetics 38: 402-418.

45. Graaf DA, Hoeken H, Sanders J, Beentjes JW (2012) Identification as a mechanism of narrative persuasion. Communication Research 39: 802-823.

46. Slater MD, Rouner D (2012) Entertainment-education and elaboration likelihood: Understanding the processing of narrative persuasion. Communication Theory 12: 173-191.

47. Banerjee SC, Greene K (2012) Role of transportation in the persuasion process: Cognitive and affective responses to antidrug narratives. Journal of Health Communication 17: 564-581. [crossref]

48. Gollust SE, Lantz PM, Ubel PA (2009) The polarizing effect of news media messages about the social determinants of health. American Journal of Public Health 99: 21602167. [crossref]

49. Schank RC, Berman T (2006) Living stories: Designing story-based educational experiences. Narrative Inquiry 16: 220-228.

50. Gabay G (2020) From the crisis in acute care to post-discharge resilience-The communication experience of Geriatric patients: A qualitative study. Scandinavian Journal of Caring Sciences. 
51. Green PJ, Douglas C, Goldberg SA (1981) General approach to product design optimization via conjoint analysis. Journal of Marketing 45: 17-37.

52. Gofman A, Moskowitz HR (2010) Isomorphic permuted experimental designs and their application in conjoint analysis. Journal of Sensory Studies 25: 127-145.

53. Moskowitz HR (1997) Base size in product testing: A psychophysical viewpoint and analysis. Food Quality and Preference 8: 247-255.

54. Gabay G, Gere A, Stanley J, Habsburg-Lothringen C, Moskowitz HR (2019) Health threats awareness-responses to warning messages about Cancer and smartphone usage. Cancer Studies Therapeutics Journal 1-10.

55. Orme B (2010) Getting started with conjoint analysis: strategies for product design and pricing research second edition. Madison: Research Publishers LLC.
56. Ratanawongsa N, Karter AJ, Parker M, Heisler LM, Moffet HH, et al. (2013) Communication and medication refill adherence: the diabetes study of northern California. JAMA Internal Medicine 173: 210-218. [crossref]

57. Gabay G (2015) Perceived control over health, communication and patient-physician trust. Patient Education and Counseling 98: 1550-1557. [crossref]

58. Gabay G (2016) Exploring perceived control and self-rated health in re-admissions among younger adults: A retrospective study. Patient Education and Counseling 99: 800-806. [crossref]

59. Gabay G, Moskowitz HR (2012) The algebra of health concerns: implications of consumer perception of health loss, illness and the breakdown of the health system on anxiety. International Journal of Consumer Studies 36: 635-646. 